\title{
EXECUÇÃO INADEQUADA DE ESTACA RAIZ EM ITAITUBA - PA: ESTUDO DE CASO
}

\author{
MATOS, RODRIGO DANIEL DE MIRANDA \\ Graduando em Engenharia Civil \\ UFOPA - Campus Itaituba \\ Itaituba - Pará - Brasil \\ rodrigomiranda01.rm@gmail.com
}

\author{
LEITE, JONAS DOS SANTOS \\ Professor do Curso de Engenharia Civil \\ UFOPA - Campus Itaituba \\ Itaituba - Pará - Brasil \\ eng.leite@hotmail.com
}

\author{
PINHEIRO, BEATRIZ DA SILVA \\ Graduanda em Engenharia Civil \\ UFOPA - Campus Itaituba \\ Itaituba - Pará - Brasil \\ biapiheiro29@outlook.com
}

\author{
TAPAJÓS, LUAMIM SALES \\ Professor do Curso de Engenharia Civil \\ UFOPA - Campus Itaituba \\ Itaituba - Pará - Brasil \\ luamimtapajos@hotmail.com
}

\section{RESUMO}

O presente trabalho trata de um estudo de caso acerca da execução de estacas do tipo raiz em Itaituba - PA de forma inadequada e suas consequências, tendo como objetivo conscientizar a comunidade técnico científica da construção civil sobre os prejuízos financeiros e de segurança estrutural pela execução inadequada de determinados métodos, por meio de estudo de caso. A metodologia do trabalho foi baseada no projeto de fundações do edifício em questão, e análise do método de execução da estaca raiz, comparando com o método usado para execução das estacas de forma inadequada, verificando a resistência a capacidade de carga obtida, por meio da prova de carga realizada no local. A prova de carga, apontou que a resistência das estacas executadas ficou bem abaixo da resistência esperada, apontando prejuízo estimado em 300 mil reais para a construtora da obra.

Palavras-chave: Fundações, Estaca Raiz, Prova de Carga Estática.

\section{ABSTRACT}

The present work deals with a case study on the execution of root-type piles in Itaituba - PA, inappropriately and with consequences, with the objective of raising the awareness of the technical scientific community of civil construction about the losses of financial and structural security resulting from inadequate execution of selected methods, and your case study. The work methodology was based on the design of the foundations in question and on the analysis of the method of execution of the root root, comparing with the method used to execute the piles in an inadequate way, verifying the resistance of the load capacity, through the proof of load carried out on site. The load test, aimed at the resistance of the piles executed, was well below the expected resistance, with an estimated loss of 300 thousand reais for construction company.

Keywords: Foundation, root stake, Static Loading Test.

\section{INTRODUÇÃO}

A Região Amazônica é uma área bastante estratégica no Brasil, devido as suas riquezas naturais, atraindo, dessa forma, diversos empreendimentos. No entanto, muitas vezes os empreendimentos não são acompanhados pelo desenvolvimento da região, dificultando a execução dos mesmos no que diz respeito à construção civil, devido à logística complexa de acesso, escassez de mão de obra qualificada e equipamentos mais sofisticados disponíveis, sendo esses fatores prejudiciais ainda mais potencializados no interior da Amazônia.

Itaituba é um município localizado no sudoeste do Pará, com uma população estimada em mais de 100.000 habitantes (IBGE, 2018), com vocação para a exploração do minério e extrativismo vegetal, sendo a segunda maior cidade da região Oeste do Pará. Além desses fatores, o referido município tornou-se estratégico devido ao escoamento de soja oriunda do Mato Grosso para exportação pelo Rio Tapajós. Assim, Itaituba passou a receber diversos investimentos, sejam privados ou públicos.

Dentre os investimentos, é possível destacar a construção da sede de um órgão público em Itaituba, orçado em pouco mais de $\mathrm{R} \$ 4.300,00$, com 4 pavimentos e fundações projetadas para serem executadas com estacas raiz. SCHPUN e 
QUERELLI (2019) comentam que historicamente estacas raiz de até $410 \mathrm{~mm}$ de diâmetro são comumente executadas no país, no entanto, essa realidade é diferente no interior da Amazônia, como se vê na referida obra, que prevê estacas com diâmetro máximo de $310 \mathrm{~mm}$, porém encontrou-se dificuldade em conseguir empresas especializadas e com equipamentos disponíveis para executar esse tipo de fundação. Essa complexidade na logística de acesso à região torna mais difícil sua execução, devido à precariedade das estradas que ligam o município aos grandes centros industriais fornecedores de materiais, bem como a carência de empresas especializadas em determinados segmentos da construção civil, sendo necessária a contratação de empresas de outras cidades.

Dessa forma, este trabalho apresenta um estudo de caso realizado na obra em questão quanto à execução das estacas raiz, onde verificou-se que o método adotado para execução das mesmas não era compatível com aquele apresentado na NBR 6122 (2010), seja pelos processos adotados quanto pelo equipamento utilizado. Destaca-se o estudo realizado por CORRÊA et al. (2006), onde os autores verificaram que as estacas raiz analisadas por eles não seguiam as recomendações normativas estabelecidas, atingindo uma capacidade resistente abaixo da estimada. Assim, o objetivo deste artigo é apresentar o resultado da prova de carga estática realizada em estacas raiz executadas de maneira inadequada, quantificando a capacidade de carga das estacas obtidas dessa forma, apontando os riscos e prejuízos obtidos por conta desse erro de execução, visto que o controle executivo é um assunto de extrema importância, como comenta LIMA (2014).

\section{REFERENCIAL TEÓRICO}

\subsection{Procedimentos para Execução de estaca Raiz}

A grandeza fundamental para o projeto de fundações profundas por estacas é a carga admissível (se o projeto for feito em termo de valores característicos) ou carga resistente de projeto (quando for feito em termos de valores de projeto). Essas cargas ou tensões devem obedecer, simultaneamente, ao estado limite último e de serviço, para cada elemento isolado de fundação e para o conjunto. O projeto de fundações consta de memorial de cálculo e dos respectivos desenhos executivos, com as informações técnicas necessárias para o perfeito entendimento e execução da obra. A elaboração do memorial de cálculo é obrigatória, devendo estar disponível quando solicitado.

Entendido os conceitos iniciais que uma fundação profunda necessita obedecer, a NBR 6122 (2010) define a estaca raiz como uma estaca moldada in loco, em que a perfuração é revestida integralmente em solo, por meio de segmentos de tubos metálicos (revestimento) que vão sendo rosqueados à medida que a perfuração é executada. Quanto ao revestimento, CORRÊA et al. (2006) comentam que antes da nova revisão, a NBR 6122 (1996) não apresentava a nomenclatura de estaca raiz, bem como alertavam para o entendimento que essa norma não previa a obrigatoriedade de completo revestimento para execução das estacas, podendo acarretar em menor capacidade resistente do que havia sido projetada.

A estaca raiz é armada em todo seu comprimento e a perfuração é preenchida por uma argamassa de cimento e areia. A perfuração em solo é executada por meio de perfuratriz rotativa ou rotopercussiva que desce o revestimento através de rotação com o uso de circulação direta de água injetada no seu interior. Após o termino da perfuração e antes do início do lançamento da argamassa, limpa-se internamente o furo através da utilização da composição de lavagem e posteriormente procede-se a descida da armadura, que pode ser montada em feixe ou em gaiola, que é apoiada no fundo do furo. O furo é preenchido com argamassa mediante a bomba de injeção, através de um tubo descido até a ponta da estaca. O preenchimento é feito de baixo para cima até a expulsão de toda a água de circulação contida no interior do revestimento. Após o preenchimento do furo, inicia-se a extração do revestimento. Periodicamente, coloca-se a cabeça de injeção no topo do revestimento e aplica-se pressão que pode ser de ar comprimido ou através da bomba de injeção de argamassa. Após a aplicação da pressão e retirada dos tubos de revestimento, o nível de argamassa é completado.

No caso de estacas com argamassa inadequada abaixo da cota de arrasamento ou estacas cujo topo resulte abaixo da cota de arrasamento prevista, deve-se fazer a demolição do comprimento e a recomposição até a cota de arrasamento. $\mathrm{O}$ material a ser utilizado na recomposição das estacas deve apresentar resistência não inferior à da argamassa da estaca. A Figura 1 mostra o procedimento a ser adotado para execução da estaca raiz. 


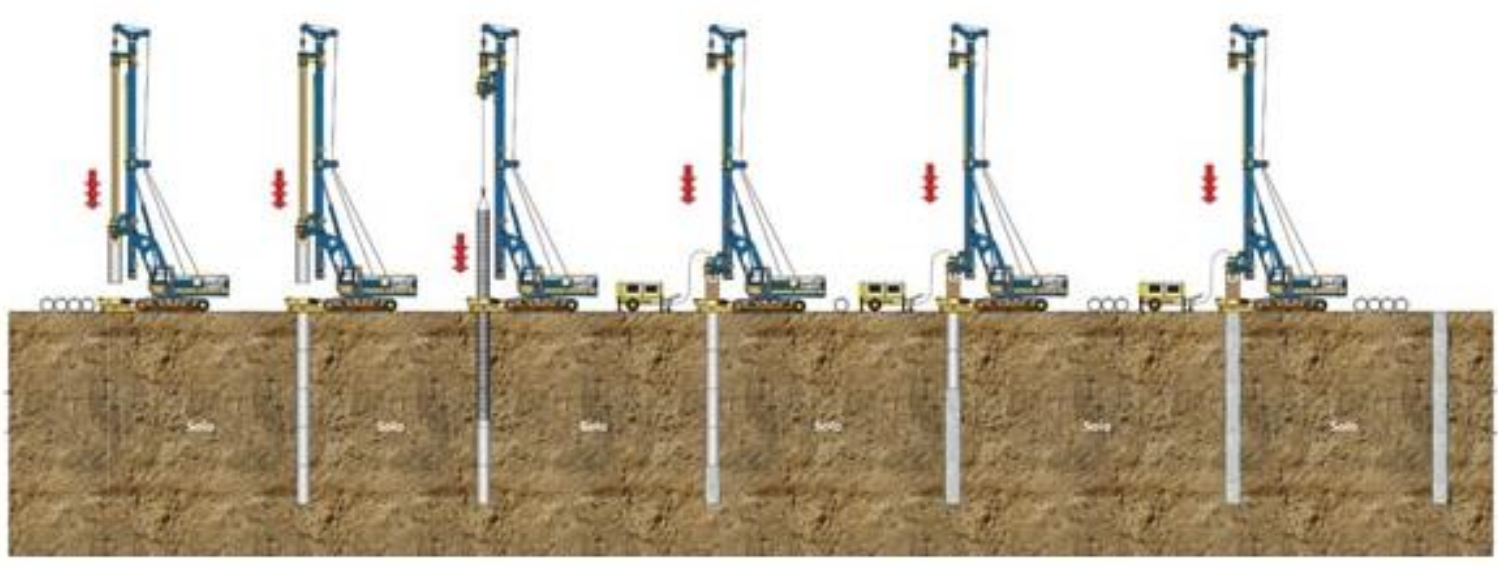

Figura 1 - Procedimento para execução de estaca raiz (PEREIRA, 2018)

\subsection{Resistência das Estacas}

A NBR 6122 (2010) indica que a carga de ruptura de estacas pode ser determinada pela realização de provas de carga, conforme recomendações da NBR 12131 (2006) e que, no projeto, estacas escavadas devem absorver pelo menos 80\% da carga de trabalho em seu fuste, o que concorda com a observação de NOGUEIRA (2004), onde as estacas raiz por ele analisadas apresentavam $96 \%$ de resistência no fuste. A capacidade de carga da estaca é atingida quando ocorrer ruptura nítida caracterizada por deformações continuadas sem novos acréscimos de carga. No entanto, é possível que a ruptura não seja nítida, seja pelo fato da capacidade de carga da estaca ser maior que a carga aplicada pelo sistema de reação utilizado no ensaio, ou então quando as estacas apresentam recalques elevados, o que vai ao encontro do observador por AMANN e MASSAD (2000), onde a maior parte das estacas ensaiadas em provas de carga não atingiram ruptura física.

Para esses dois casos, pode-se extrapolar a curva carga-recalque para avaliar a ruptura, nesse caso a carga de ruptura pode ser convencionada como aquela que corresponde, na curva carga-deslocamento mostrada na Figura 2, ao recalque obtido pela Equação 1. A Figura 3 mostra o sistema de ensaio de prova de carga estática adotado por SCHPUN e QUERELLI (2019).

$$
\Delta \mathrm{r}=\frac{\mathrm{PL}}{\mathrm{AE}}+\frac{\mathrm{D}}{30}
$$

Onde:

$\Delta_{r}$ é o recalque de ruptura convencional;

$P$ é a carga de ruptura convencional;

$L$ é o comprimento da estaca;

$A$ é a área da seção transversal da estaca;

$E$ é o módulo de elasticidade do material da estaca;

$D$ é o diâmetro do círculo inscrito à estaca.

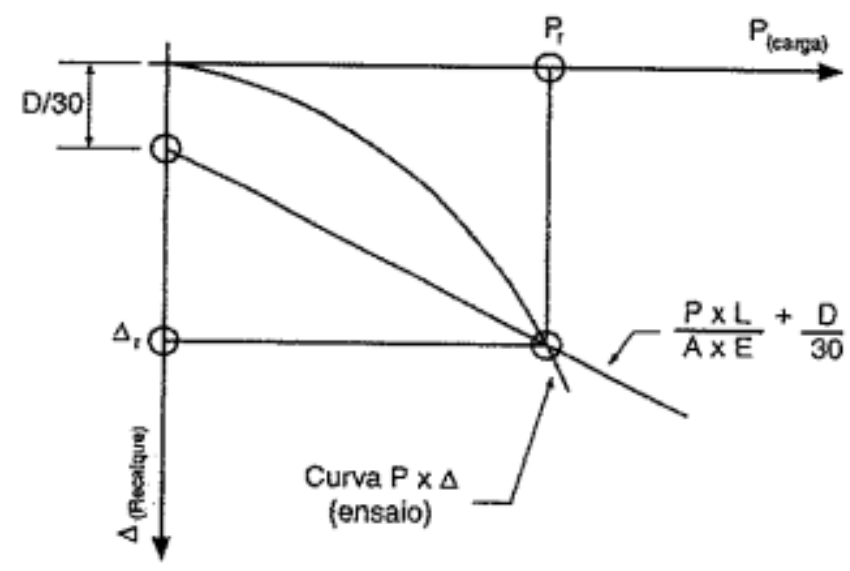


Figura 2 - Carga de ruptura convencional (NBR 6122, 2010)

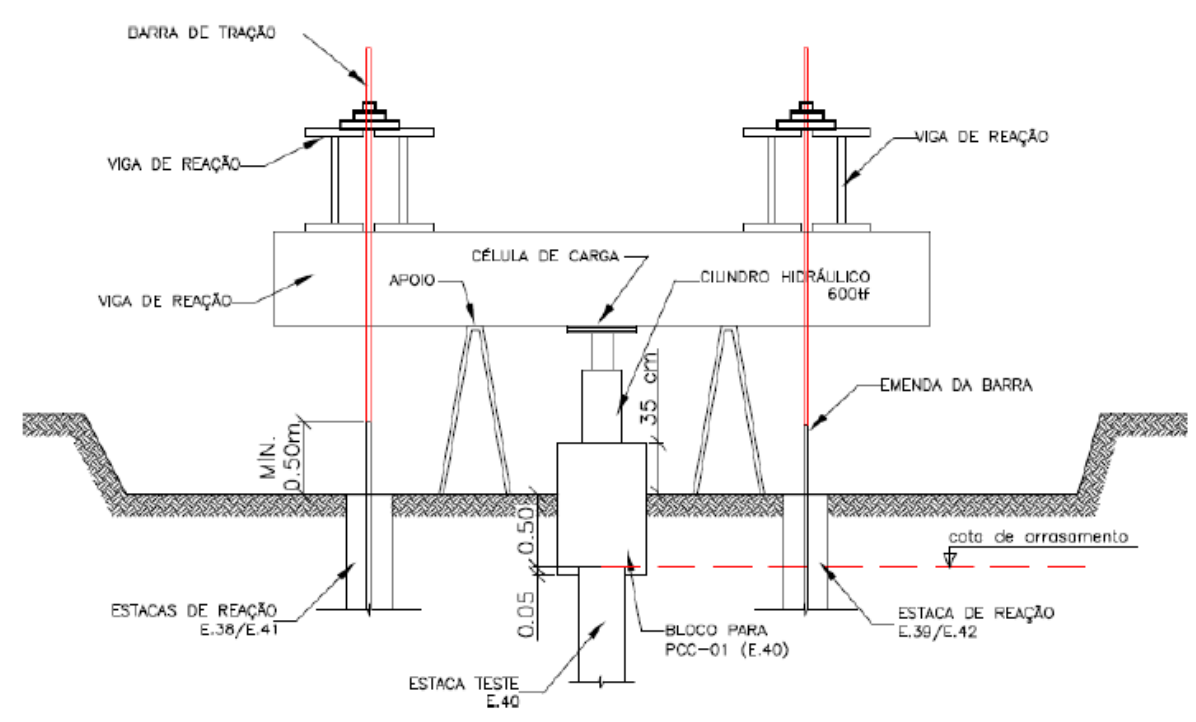

Figura 3 - Corte esquemático da prova de carga estática (SCHUPUN E QUERELLI, 2019)

\subsection{Métodos semiempíricos}

Descrito as técnicas acima acerca da execução da estaca raiz e como é feito sua prova de carga, é essencial entender os métodos de cálculo de resistências da mesma, para assim, ser feito os projetos de estacas e blocos de coroamento, baseado nos dados do solo (SPT). Atualmente são mais utilizados 3 métodos, o de AOKI - VELLOSO, DÉCOURT QUARESMA, E TEIXEIRA 1996, no qual o método AOKI E VELLOSO, que resulta a equação, em que a primeira parcela refere-se à resistência de ponta e a segunda à resistência lateral:

$$
R=\frac{k N s p t}{F 1} A p+\frac{U}{F 2} \sum_{1}^{n}(\alpha K N s p t \Delta L)
$$

Pelo fato de a metodologia apresentada, que utiliza os valores de SPT, ter sido elaborada, inicialmente, em relação aos resultados de ensaio estáticos de cone (CPT), faz - se necessário para aplica - la nos ensaios de penetração dinâmica, adotar o coeficiente $k$ e a razão de atrito $\alpha$, que dependem do tipo de solo, e os coeficientes $F 1$ e $F 2$, que dependem do tipo de estaca, sendo fatores de correção das resistências de ponta e lateral, respectivamente, os quais levam em consideração as diferenças de comportamentos entre a estaca e o cone estático. (Marcos Fábio.2014). DECOURT E QUARESMA, segundo (Jean Felix, 2014) apresentam um processo expedito para determinação da carga de ruptura de estacas, com base apenas ( e diretamente) nos resultados fornecidos por sondagens à percussão. Os autores ressaltam que o método elaborado não visa a obtenção de valores exatos, mas sim de estimativas bastante aproximadas, seguras, e principalmente de fácil determinação. Decourt e Quaresma sugerem os seguintes valores de resistência lateral, sem distinção quanto ao tipo de solo:

Tabela 1: Valores de adesão sugeridos por Decourt e Quaresma

\begin{tabular}{|c|c|}
\hline $\begin{array}{c}\text { SPT (Valor médio ao longo do } \\
\text { fuste) }\end{array}$ & $\begin{array}{c}\text { Adesão } \\
\text { (Kpa) }\end{array}$ \\
\hline 3 & 20 \\
\hline 6 & 30 \\
\hline 9 & 40 \\
\hline 12 & 50 \\
\hline$>15$ & 60 \\
\hline
\end{tabular}

Para a estimativa da resistência de ponta em KPa, os autores propõem a utilização da seguinte expressão: 


$$
\boldsymbol{Q p}=\boldsymbol{C} \times \boldsymbol{N}
$$

Sendo que o valor do coeficiente $\mathrm{C}$ do método depende do tipo de solo, de acordo com a tabela abaixo:

Tabela 2: Valores do coeficiente C sugeridos por Decourt e Quaresma

\begin{tabular}{|c|c|}
\hline Tipo de Solo & C (Kpa) \\
\hline Argilas & $\mathbf{1 2 0}$ \\
\hline Siltes Argilosos (Solos residuais) & $\mathbf{2 0 0}$ \\
\hline Siltes Arenosos (Solos residuais) & $\mathbf{2 5 0}$ \\
\hline Areias & $\mathbf{4 0 0}$ \\
\hline
\end{tabular}

Por fim, o método de TEIXEIRA (1996), segundo (Jean Felix,2014)o autor com base nos índices de resistência a penetração do ensaio SPT realizado nas sondagens a penetração propõe as seguintes expressões de cálculo para estimativa da capacidade das estacas:

$$
\begin{aligned}
& Q p=\alpha \times N p \\
& Q l=\beta \times N l
\end{aligned}
$$

Sendo que Np é o valor médio dos índices de resistências a penetração $\mathrm{N}$ medidos no intervalo entre quatro diâmetros acima da ponta da estaca, e um diâmetro abaixo, NL é o valor médio dos $\mathrm{N}$ medidos no ensaio SPT ao longo do comprimento do fuste da estaca, e os parâmetros alfa e beta propostos pelo autor são apresentados nas seguintes tabelas:

Tabela 3: Valores de parâmetros Alfa de Teixeira

\begin{tabular}{|c|c|c|c|c|}
\hline \multirow{2}{*}{$\begin{array}{c}\text { Tipo de Solo } \\
(4<\mathrm{N}<40)\end{array}$} & $\begin{array}{c}|c| \\
\text { Pré - moldadas de } \\
\text { concreto e metálicas }\end{array}$ & $\begin{array}{c}\text { Tipo } \\
\text { Franki }\end{array}$ & $\begin{array}{c}\text { Escavadas a céu } \\
\text { aberto }\end{array}$ & Estaca raiz \\
\hline Areia com pedregulho & $\mathbf{4 4 0}$ & $\mathbf{3 8 0}$ & $\mathbf{3 1 0}$ & $\mathbf{2 9 0}$ \\
\hline Areia & $\mathbf{4 0 0}$ & $\mathbf{3 4 0}$ & $\mathbf{2 7 0}$ & $\mathbf{2 6 0}$ \\
\hline Areia Siltosa & $\mathbf{3 6 0}$ & $\mathbf{3 0 0}$ & $\mathbf{2 4 0}$ & $\mathbf{2 2 0}$ \\
\hline Areia Argilosa & $\mathbf{3 0 0}$ & $\mathbf{2 4 0}$ & $\mathbf{2 0 0}$ & $\mathbf{1 9 0}$ \\
\hline Silte arenoso & $\mathbf{2 6 0}$ & $\mathbf{2 1 0}$ & $\mathbf{1 6 0}$ & $\mathbf{1 6 0}$ \\
\hline Silte Argiloso & $\mathbf{1 6 0}$ & $\mathbf{1 2 0}$ & $\mathbf{1 1 0}$ & $\mathbf{1 1 0}$ \\
\hline Argila Arenosa & $\mathbf{2 1 0}$ & $\mathbf{1 6 0}$ & $\mathbf{1 3 0}$ & $\mathbf{1 4 0}$ \\
\hline Argila Siltosa & $\mathbf{1 1 0}$ & $\mathbf{1 0 0}$ & $\mathbf{1 0 0}$ & $\mathbf{1 0 0}$ \\
\hline
\end{tabular}

Tabela 4: Valores de parâmetros Beta de Teixeira.

\begin{tabular}{|c|c|}
\hline Tipo de Estaca & $\mathrm{B}(\mathrm{kPa})$ \\
\hline Pré - moldadas e metálicas & 4 \\
\hline Tipo Franki & 5 \\
\hline Escavadas a céu aberto & 4 \\
\hline Estaca Raiz & 6 \\
\hline
\end{tabular}

\section{METODOLOGIA}

O estudo de caso adotado neste artigo foi realizado em uma obra de médio porte no município de Itaituba, localizado na região sudoeste do Pará, com o objetivo da construção de um prédio com quatro pavimentos, que será nomeado, neste estudo, de Bloco Padrão de Itaituba (BPI), orçada em R \$ 4.300.00,00. No seu projeto de fundações, o engenheiro adotou estacas do tipo raiz, no entanto, observou-se que o equipamento e método de execução das estacas não estava compatível com as recomendações da NBR 6122 (2010) sobre execução de estaca raiz, necessitando que fosse realizada uma prova de carga estática para mensurar a capacidade de carga das estacas executadas por esse método. Dessa forma, 
a metodologia deste trabalho aborda o método adotado para execução das estacas e o procedimento utilizado para realização da prova de carga estática.

\subsection{Execução das estacas do BPI}

O projeto de fundações do BPI contém 35 blocos de coroamento, variando entre blocos de 1 a 5 estacas. Cada bloco possuía estacas com os mesmos diâmetros. Todas as estacas foram dimensionadas com 10 metros de comprimento, verticais, seção circular e argamassa com fck de $20 \mathrm{Mpa}$. Os diâmetros das estacas variavam entre $200 \mathrm{~mm}, 250 \mathrm{~mm}$ e $310 \mathrm{~mm}$. As armaduras longitudinais eram formadas por barras de 12,5 mm de diâmetro de aço CA-50, sendo composta por 4 barras para as estacas de $200 \mathrm{~mm}, 5$ barras para as estacas de $250 \mathrm{~mm}$ e 6 barras para as estacas de $310 \mathrm{~mm}$. Além disso, a armadura transversal é composta por estribos espirais com aço CA-60 de 5 mm de diâmetro.

A empresa responsável pela construção do BPI contratou uma empresa especializada em execução de fundações e sondagem em solos para construção civil, para que fossem executadas as estacas da obra em questão. Vale ressaltar que a empresa subcontratada possui sede na capital do estado, Belém-PA, devido à indisponibilidade de empresas com esse perfil no município de Itaituba-PA. Observou-se que as estacas foram executadas com um equipamento que permitia a rotação de uma haste com um trado na sua extremidade, sem a presença de tubos metálicos, que é utilizado para execução de estacas raiz. A Figura 3 mostra o procedimento de execução das estacas do BPI.

Apesar da incompatibilidade de equipamentos e procedimentos verificados, a empresa especializada em fundações emitiu um laudo atestando que o serviço oferecido era de uma estaca raiz, enquanto que o projetista e a equipe de fiscalização da obra apresentavam entendimento diferente, apontando, principalmente, a ausência dos tubos metálicos de revestimento, que caracterizam a estaca raiz. Dessa forma, a solução adotada pela equipe responsável pela construção do BPI foi de realização de uma prova de carga, de modo que se pudesse determinar a capacidade de carga das estacas executadas por esse método.

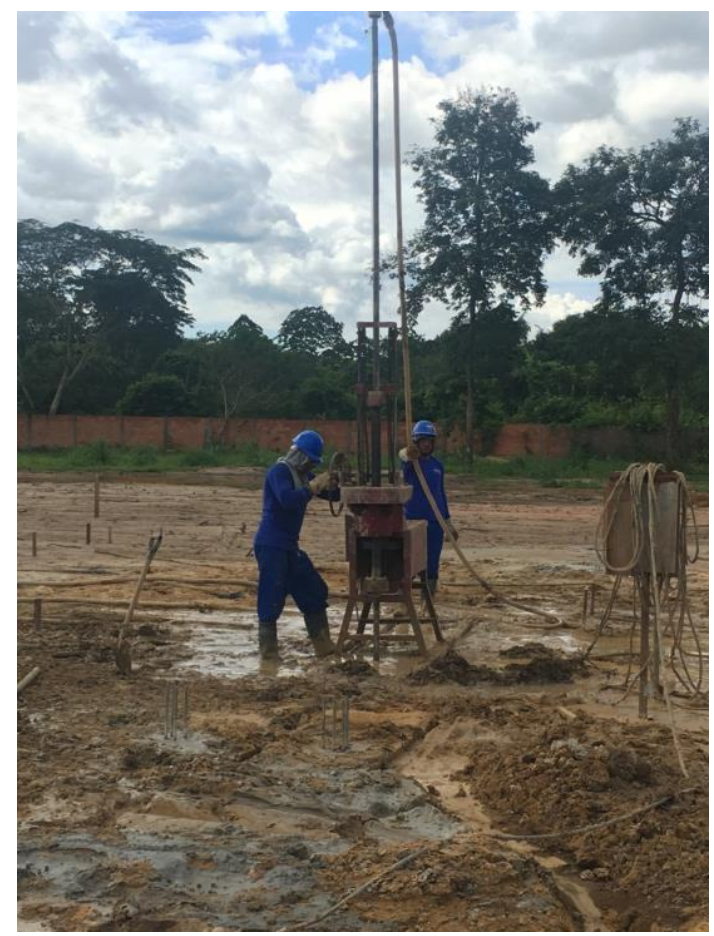

a) Equipamento para execução das estacas

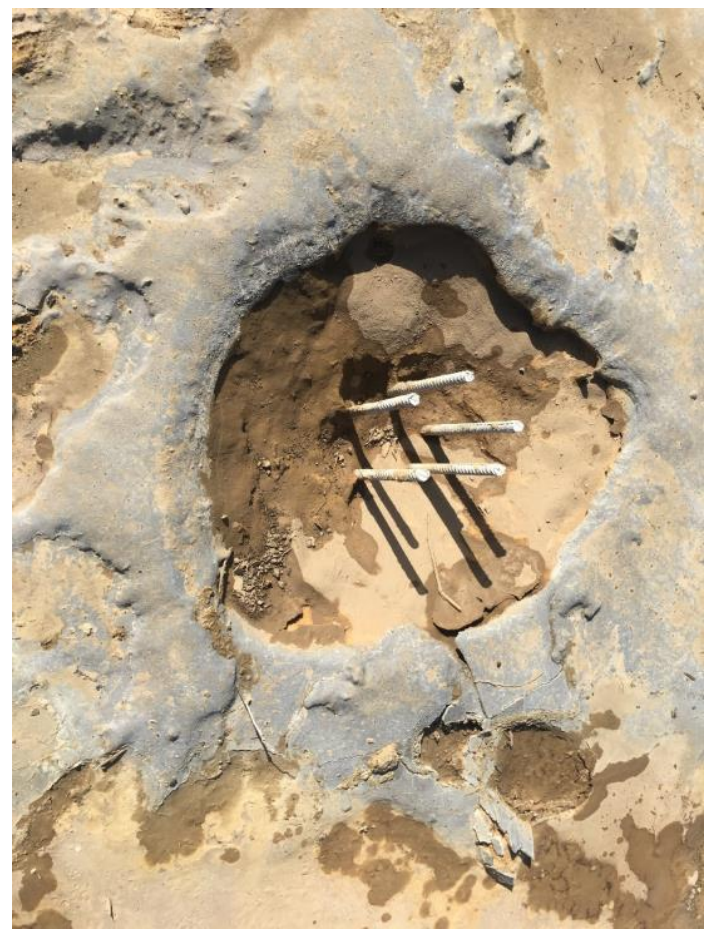

b) Estaca após execução

Figura 4 - Execução das estacas do BPI

\subsection{Execução da prova de carga estática}

Para realização da prova de carga, foi adotada uma estaca com $310 \mathrm{~mm}$ de diâmetro pertencente a um dos blocos, com carga de projeto adotada de $42 \mathrm{Tf}$. Para tanto, foi previsto o carregamento da estaca até $70 \mathrm{Tf}$, ou seja, igual a 1,67 vezes a carga de trabalho de 42 Tf, conforme preconiza a NBR 6122 (2010). SCHPUN e QUERELLI (2019) afirmam que o ideal para realização de prova de carga estática é atingir duas vezes o valor da carga de trabalho, porém existe a 
dificuldade em se chegar a esse valor, como também aborda ALONSO (1993). O ensaio foi realizado com carregamento lento de acordo com a NBR 12131 (2006), aplicando-se passos de carga de 7 Tf. Deste modo, em cada estágio, a carga foi mantida até a estabilização dos deslocamentos, ou no mínimo por 30 min. Em cada estágio, os deslocamentos foram lidos imediatamente após a aplicação da carga correspondente, seguindo-se leituras decorridos 2min, 4min, $8 \mathrm{~min}$, 15min, 30min e assim por diante, contados a partir do início do estágio, ou até se atingir a estabilização. Terminada a fase de carregamento, a carga máxima do ensaio foi mantida durante $12 \mathrm{~h}$ entre a estabilização dos recalques e o início do descarregamento.

O sistema de reação foi formado por três vigas de reação posicionadas em disposição tipo "H", ancoradas em quatro estacas de reação, com tirantes do tipo Dywidag DW ST 95/105, com 32 mm de diâmetro, Foram empregadas quatro vigas de referência para o posicionamento dos relógios comparadores. Os apoios temporários das vigas de reação foram proporcionados através de cavaletes de madeira montados na obra, seguindo projeto fornecido pela empresa. $\mathrm{O}$ carregamento foi aplicado na estaca ensaiada através de um conjunto bomba e macaco hidráulico com capacidade de 300 Tf. A carga aplicada foi monitorada através do manometro e da célula de carga. Terminada a fase de carregamento, a carga máxima do ensaio foi mantida durante $12 \mathrm{~h}$ entre a estabilização dos recalques e o início do descarregamento. A Figura 4 mostra o sistema de ensaio adotado na prova de carga.

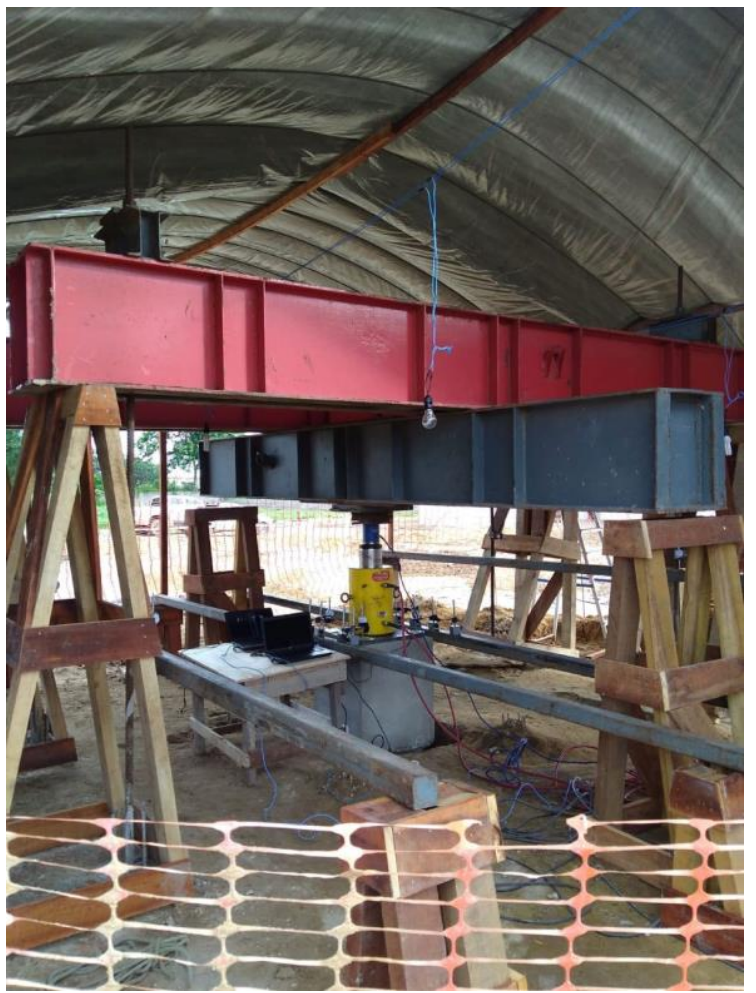

Figura 5 - Sistema de ensaio da prova de carga

\section{RESULTADOS}

Com a utilização da célula de carga e dos relógios comparadores, foi possível obter a carga aplicada ao sistema de ensaio e os recalques relativos para a respectiva carga. Como foram utilizados 4 relógios comparadores, adotou-se a média aritmética dos resultados registrados pelos mesmos para obtenção do recalque médio, a ser considerado neste estudo.

A Figura 5a mostra o gráfico da curva Carga-Recalque obtido no ensaio. Observa-se que foi possível chegar ao incremento de carga até o quinto passo de carga, equivalente a 35Tf, uma vez que antes de completar o sexto passo de carga, o sistema se estabilizou em 37Tf, com um recalque médio de $42 \mathrm{~mm}$. Apesar da carga máxima atingida ser equivalente a 37Tf, observou-se que a partir do terceiro passo de carga o aumento do recalque foi muito alto, dessa forma, julgou-se apropriado considerar a carga de ruptura convencional preconizada pela NBR 6122 (2010), como mostra a Figura 2 e Equação 1 deste artigo. Dessa forma, a Figura 5b mostra o valor obtido para carga de ruptura convencional, equivalente a $27 \mathrm{Tf}$. 


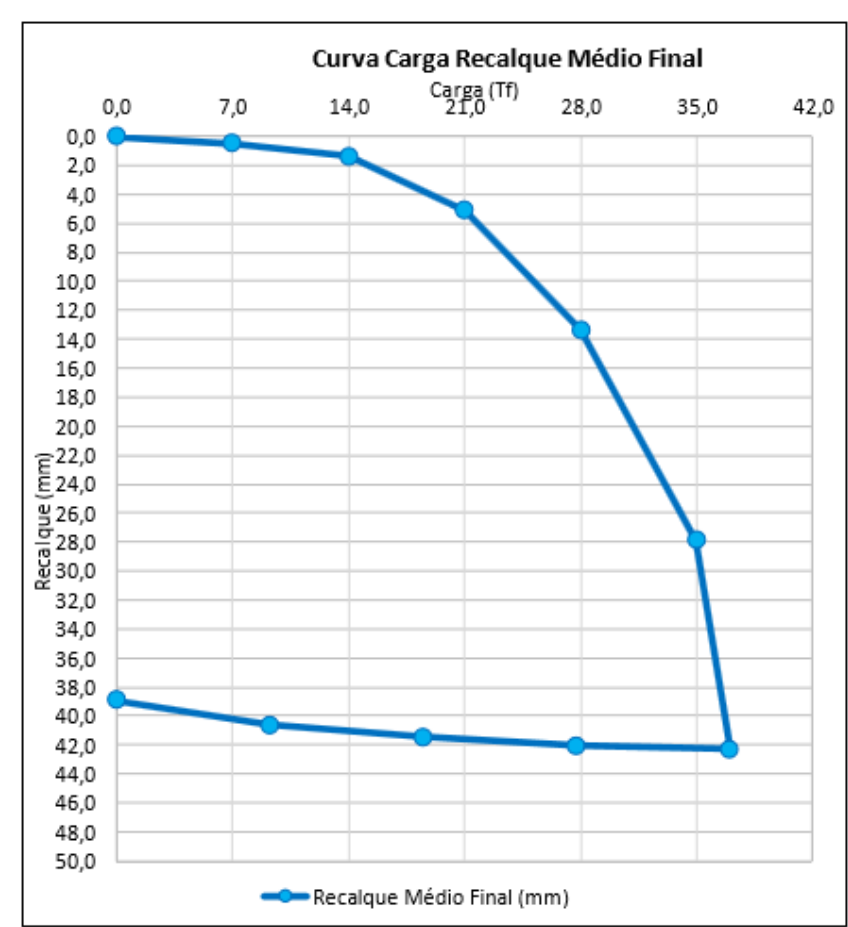

a) Recalque médio

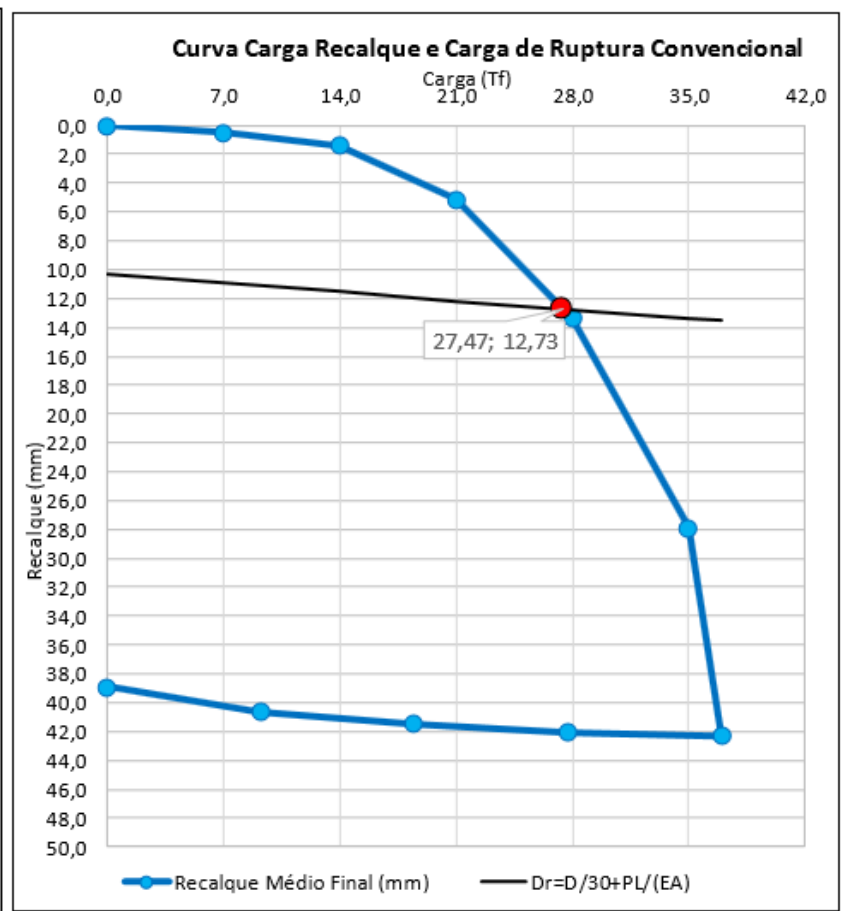

b) Ruptura convencional

Figura 6 - Curva Carga-Recalque

Apesar da estimativa de carga máxima aplicada ao ensaio ser de 70Tf, que corresponde a 1,67 vezes a carga de trabalho prevista em projeto (42Tf), o sistema só permitiu atingir 37Tf, enquanto que a carga de ruptura convencional foi calculada em 27Tf, de acordo com as recomendações da NBR 6122 (2010). Dessa forma, considerando-se o coeficiente de segurança adotado para fundações profundas equivalente a 2,0, a resistência de projeto da estaca ensaiada é equivalente a 13,5Tf, ou seja, apenas $32 \%$ da carga prevista em projeto. Além disso, mesmo a carga de ruptura convencional e a carga máxima atingida no ensaio realizado são inferiores à carga de trabalho prevista em projeto, colocando em risco a segurança estrutural do edifício em questão.

\section{CONCLUSÃO}

Este artigo abordou a metodologia recomendada pela NBR 6122 (2010) para execução de estacas raiz, bem como apresentou as recomendações da NBR 12131 (2006) para realização de prova de carga estática em estacas de fundações profundas. O objetivo do trabalho foi apresentar, por meio de um estudo de caso, métodos de execução de estacas que são vendidos como estaca raiz, porém não atendem aos requisitos normativos para se categorizar como estaca raiz, e os impactos negativos obtidos com essa ação.

Por meio da execução da prova de carga, observou-se que a resistência da estaca executada apresentou apenas $32 \%$ da resistência de projeto. Além da resistência, o aspecto final da estaca obtida com a utilização do equipamento mostrado pode proporcionar o não respeito aos cobrimentos de projeto, levando ao desgaste precoce da estrutura. Vale ressaltar, também, que a alternativa adotada para corrigir o problema detectado foi de rescisão com a empresa que estava executando as fundações do BPI e contratação de nova empresa que utilizava equipamentos adequados, necessitando da realização de reforços na fundação. O prejuízo estimado da empresa foi de $\mathrm{R} \$ 300.000,00$.

Ademais, observou - se que a prova de carga realizada por SCHUPUN E QUERELLI (2019) em seus estudos, comprovam que a utilização correta dos equipamentos, permitem que a execução das estacas do tipo raiz fosse feita da maneira prevista em norma, garantindo assim que sua resistência fosse maximizada até o limite estrutural para qual foi projetada. Assim como LIMA (2016) afirma por meio de prova de carga que a utilização dos métodos semiempíricos, atrelado a execução corretas das estacas, possibilitam fazer estimativas de cargas muito próximas ao real, corroborando assim, para uma maior segurança na execução das estacas do tipo raiz. Neste sentido, pode - se afirmar que as estacas do tipo raiz executadas em Itaituba - PA, não obtiveram êxito em sua resistência por não seguirem as recomendações de execução previstas em norma, causando enorme transtorno e retrabalhos. 
Apesar das várias evidências de que o equipamento apresentado não se caracterizava como adequado para realização de estacas raiz, essa prática é muito comum em diversas cidades da Amazônia, principalmente nos interiores, devido ao baixo número de engenheiros especializados em projetos e execução de fundações. Dessa forma, este artigo colabora com a conscientização no meio técnico para os cuidados relacionados às especificações determinadas em projetos e nas recomendações normativas vigentes, apontando os principais prejuízos obtidos.

\section{AGRADECIMENTOS}

Os autores agradecem à Universidade Federal do Oeste do Pará (UFOPA) e ao Campus Universitário de Itaituba (CITB) pelo apoio e fomento à realização deste e outros trabalhos.

\section{REFERÊNCIAS}

AMAN, K.A.P.; MASSAD, F. Estacas Raiz: Avaliação Crítica e Proposta de Melhoria dos Métodos SemiEmpíricos de Estimativa da Carga de Ruptura. Seminário de Fundações Especiais, São Paulo, 2000.

ASSOCIAÇÃO BRASILEIRA DE NORMAS TÉCNICAS. NBR 6122: Projeto e Execução de fundações. Rio de Janeiro, 2010.

ASSOCIAÇÃO BRASILEIRA DE NORMAS TÉCNICAS. NBR 12131: Estacas - Prova de carga estática. Rio de Janeiro, 2006.

PEREIRA, C. Estaca Raiz: Características, Processo Executivo, Vantagens e Desvantagens. Escola Engenharia, 2018.

SCHPUN, B.; QUERELLI, A. Estaca Raiz $\Phi 500$ mm: Procedimentos Executivos, Detalhamento e Prova de Carga Estática até 5050 kN. $9^{\circ}$ Seminário de Engenharia de Fundações Especiais e Geotecnia, São Paulo, 2019.

CORRÊA, C.N.; OLIVEIRA, M.A.; JÚNIOR, W.P. Estaca raiz: Um caso de Ruptura. Congresso Brasileiro de Mecânica dos Solos, São Paulo, 2006

LIMA, D.R. Contribuição ao estudo do desempenho de estacas do tipo raiz. Dissertação (Mestrado), Universidade Federal do Ceará. Fortaleza, Ceará, 2014.

AOKI, N.; VELLOSO, D.A. Na approximate method to estimate the bearing capacity of piles. In: Pan-American Conference of Soil Mechanics and Foundation Engineering. Buenos Aires, Argentina. Proccedings...Buenos Aires: ISSMGE, v. 1, p. 215-218, 1975.

NOGUEIRA, R.C.R. Comportamento de estacas tipo raiz, instrumentadas, submetidas à compressão axial, em solo de diabásio. Dissertação (Mestrado), Universidade Estadual de Campinas, São Paulo, 2004.

ALONSO, U. (1993). Reavaliação do Dimensionamento Estrutural de Estacas Raiz face à exigência do ensaio MB-3472 da ABNT - Solos e Rochas, São Paulo, 16 (1), p. 41-44.

DÉCOURT, L.; QUARESMA, A.R. Capacidade de carga de estacas a partir de amostras de SPT. Congresso Brasileiro de Mecânica dos Solos e Engenharia de Fundações. Rio de Janeiro, 1978.

TEIXEIRA, A. H.; GODOY, N.S. de; Análise, projeto e execução de fundações rasas. Fundações: Teoria e prática; $2^{\circ}$ edição; PINI; São Paulo; 1998. 227-264 p. 